\title{
Generation and analysis of expressed sequence tags from the ciliate protozoan parasite Ichthyophthirius multifiliis Jason W Abernathy ${ }^{1}$, Peng Xu${ }^{1}$, Ping Li ${ }^{1}$, De-Hai Xu${ }^{2}$, Huseyin Kucuktas ${ }^{1}$, Phillip Klesius ${ }^{2}$, Covadonga Arias ${ }^{1}$ and Zhanjiang Liu*1
}

\begin{abstract}
Address: ${ }^{1}$ The Fish Molecular Genetic and Biotechnology Laboratory, Department of Fisheries and Allied Aquacultures and Program of Cell and Molecular Biosciences, Aquatic Genomics Unit, Auburn University, AL 36849 USA and 2Aquatic Animal Health Research Laboratory, Agricultural Research Service, United States Department of Agriculture, Post Office Box 952, Auburn, AL 36831 USA

Email: Jason W Abernathy - abernjw@auburn.edu; Peng Xu - xupeng1@auburn.edu; Ping Li - pli@acesag.auburn.edu; De-Hai Xu - DXu@msastoneville.ars.usda.gov; Huseyin Kucuktas - hkucuktas@acesag.auburn.edu; Phillip Klesius - pklesius@msa-stoneville.ars.usda.gov; Covadonga Arias - carias@acesag.auburn.edu; Zhanjiang Liu* - zliu@acesag.auburn.edu

* Corresponding author
\end{abstract}

Published: 18 June 2007

BMC Genomics 2007, 8:176 doi:10.1186/147|-2164-8-176
Received: 21 November 2006

Accepted: 18 June 2007

This article is available from: http://www.biomedcentral.com/I47I-2/64/8/I76

(C) 2007 Abernathy et al; licensee BioMed Central Ltd.

This is an Open Access article distributed under the terms of the Creative Commons Attribution License (http://creativecommons.org/licenses/by/2.0), which permits unrestricted use, distribution, and reproduction in any medium, provided the original work is properly cited.

\begin{abstract}
Background: The ciliate protozoan Ichthyophthirius multifiliis (Ich) is an important parasite of freshwater fish that causes 'white spot disease' leading to significant losses. A genomic resource for large-scale studies of this parasite has been lacking. To study gene expression involved in Ich pathogenesis and virulence, our goal was to generate expressed sequence tags (ESTs) for the development of a powerful microarray platform for the analysis of global gene expression in this species. Here, we initiated a project to sequence and analyze over 10,000 ESTs.
\end{abstract}

Results: We sequenced 10,368 EST clones using a normalized cDNA library made from pooled samples of the trophont, tomont, and theront life-cycle stages, and generated 9,769 sequences (94.2\% success rate). Post-sequencing processing led to 8,432 high quality sequences. Clustering analysis of these ESTs allowed identification of 4,706 unique sequences containing 976 contigs and 3,730 singletons. These unique sequences represent over two million base pairs $(\sim 10 \%$ of Plasmodium falciparum genome, a phylogenetically related protozoan). BLASTX searches produced 2,5 I 8 significant (E-value $<10^{-5}$ ) hits and further Gene Ontology $(\mathrm{GO})$ analysis annotated I,008 of these genes. The ESTs were analyzed comparatively against the genomes of the related protozoa Tetrahymena thermophila and P. falciparum, allowing putative identification of additional genes. All the EST sequences were deposited by dbEST in GenBank (GenBank: EG957858-EG966289). Gene discovery and annotations are presented and discussed.

Conclusion: This set of ESTs represents a significant proportion of the Ich transcriptome, and provides a material basis for the development of microarrays useful for gene expression studies concerning Ich development, pathogenesis, and virulence.

\section{Background}

The ciliate protozoan Ichthyophthirius multifiliis (Ich)is one of the most devastating pathogens. It infects fish skin and gills, and causes white spot diseases in many species of freshwater fish worldwide, which leads to significant losses in the aquaculture industry. The ciliate parasite has 
three main life-cycle stages: the reproductive tomont, the infective theront, and a parasitic trophont [1-3]. The mature trophont drops off the host to become the tomont where it attaches to a substrate, and undergoes multiple divisions to produce hundreds to thousands of tomites within a cyst. Tomites bore their way through the cyst into water, and differentiate into theronts that infect fish. Once they burrow into the fish epithelium, theronts become trophonts that feed and mature in the host.

In spite of great losses caused by Ich to the aquaculture industry, molecular studies of the parasite have been scarce [see a recent review [4]]. Limited studies have concentrated on immune responses of the host and factors affecting them [5-11]. One of the difficulties for the studies of Ich is the problem involved in long-term maintenance of Ich isolates. Ich isolates appear to lose infectivity or become senescent after a certain number of passages [12-15]. Most often a significant decrease in infectivity is observed after about 50 passages [15]. Not only the infectivity decreases with higher numbers of passages, but also the development of the parasite as measured by the period required for trophonts to emerge from fish [15].

The Ich senescence phenomenon is interesting not only as a developmental biology issue, but also as a potential research system to study the virulence factors involved in the parasite pathogenesis. Assuming the life cycles of Ich and its infectivity are controlled by gene products, then it would be of great interest to learn what genes are involved in the loss of infectivity, and in the slowing down of its development. However, as very limited molecular information is available from Ich, in-depth research is limited by the lack of information and the lack of genomic resources.

EST analysis is one of the most effective means for gene discoveries, gene expression profiling, and functional genome studies [16-23]. It is also one of the most efficient ways for the identification of differentially expressed genes [24-28]. In order to provide genomic resources for the analysis of differentially expressed genes at different developmental stages of the Ich parasite, and for the analysis of genes differentially expressed when infectivity is being lost, the objectives of this study were to create cDNA libraries suitable for the analysis of expressed sequence tags (ESTs) and to generate an EST resource for Ich to allow cDNA-based design of microarrays for the study of gene expression in relation to the passages and development of the parasite. Before this work, there were only 511 Ich sequences in the GenBank dbEST (release 100606) [29]. A brief examination of these existing EST sequences indicated that a large proportion of them were trophont only reads, histones, ribosomal proteins, and immobilization antigen-related sequences. Here we report sequenc- ing of 10,368 Ich EST clones, and generation of 8,432 high quality EST sequences. This EST resource should provide the material basis for the development of microarrays for Ich, and serve as a platform for its functional genomic studies including the development and pathogenesis of Ich, and the host-parasite interactions.

\section{Results and Discussion \\ Generation of the Ich ESTs}

As summarized in Table 1, a total of 10,368 clones were sequenced from a normalized Ich library made from pooled cells from all three life cycle stages: theront, tomont, and trophont. Readable sequences were generated with 9,769 clones (94.2\% sequencing success rate). After base calling, sequences were processed by using Phred [30,31] to eliminate low quality sequences below Q20. Sequences passing Q20 were uploaded into Vector NTI Advance 10 (Invitrogen, Carlsbad, CA) for vector trimming and removal of sequences with very short inserts $(<100 \mathrm{bp})$. The post-sequencing processing resulted in 8,432 high quality sequences.

The processed sequences were subjected to cluster analysis using Vector NTI to evaluate sequence redundancies. Of the 8,432 sequences, 4,702 sequences fell within 976 contigs while 3,730 sequences were singletons. On average, each contig contained 4.8 sequences. Taken together, the 976 contigs and the 3,730 singletons made up 4,706 unique sequences (Table 1).

The Ich genome expression appeared to be extremely polarized with a few genes expressed at very high levels. In spite of normalization, transcripts from a few genes were sequenced at very high frequencies. The top 20 contigs with the largest number of ESTs are summarized in Table 2. Of the top 20 most abundantly sequenced transcripts, four of them were detected over $0.5 \%$ of total sequences. Of these, the most abundantly sequenced EST cluster, cluster 276 with 764 ESTs, accounted for $7.36 \%$ of all sequenced clones. BLASTX searches indicated that this transcript was most similar to a hypothetical protein, TTHERM_02141640, from Tetrahymena thermophila. The second most abundantly sequenced transcript was cluster 60 with 119 ESTs. It was identified as a transcript most similar to a hypothetical protein, TTHERM_02641280, from T. thermophila. The functions of these hypothetical proteins are unknown at present. These are two transcripts sequenced at exceptionally high frequencies. Obviously, the presence of such abundant transcripts suggested a failure in the normalization processes. However, it is puzzling to us because we believe the overall normalization processes may have worked based on several other observations: 1) the overall gene discovery rate (unique sequences over all sequences analyzed) was $55.8 \%$, a reasonable rate for the sequencing depth of approximately 
Table I: A summary of the EST analysis.

\begin{tabular}{lll}
\hline Description & Number & Percentage \\
\hline Total number of clones sequenced & 10,368 & $94.2 \%$ \\
Total number of successful sequences & 9,769 & $86.3 \% 1$ \\
Number of high quality sequences & 8,432 & $55.8 \% 2$ \\
Unique sequences & 4,706 & 976 \\
Number of contigs & 4,702 & \\
Number of clones included in the contigs & 4.82 & $53.5 \% 3$ \\
Average clones per contig & 3,730 & $46.5 \%^{3}$ \\
Number of singletons & 2,518 & 2,188 \\
Number of known genes & & \\
Unique unknown genes & &
\end{tabular}

IPercentage of high quality sequences from successful sequences; ${ }^{2}$ percentage of unique sequences of the high quality sequences; ${ }^{3}$ percentage of unique sequences

10,000 clones; 2) most other anticipated highly expressed genes such as ribosomal protein genes, actin genes, tubulin genes, and dynein genes were not detected at high levels. Nonetheless, we believe that this information is relevant and important as these genes should be the subject for additional subtraction for further EST sequencing in this species. In addition, such information should provide some basic picture about the most abundantly expressed genes in the parasite. As these hypothetical protein genes are transcribed at such high levels, they may be crucially important for the growth and development, or other life-cycle processes of the parasite.

This work demonstrated that pooling of samples from all three stages of Ich life cycle followed by normalization was an effective way to reduce common messages across all three life stages. As one would expect, many structural genes would be expressed highly abundantly in all stages of the life cycle. In addition to making savings economically, pooling of samples allowed very effective normalization of these common transcripts without going through three rounds of normalization. This is consistent with our previous experience for the generation of a large number of catfish and oyster ESTs [32-36]. It is obvious that the pooling of samples from three developmental stages made it impossible to provide information concerning expression profiling in relation to developmental stages. However, such information would not be highly meaningful in normalized cDNA libraries where the major focus was to develop EST resources, rather than expression profiling. The other limitation caused by construction of a pooled cDNA library is the loss of sequencing flexibility as to the number of clones to be sequenced from each developmental stage library if they had been separately constructed.

The Ich transcribed sequences are highly A/T-rich, similar to the situation in $T$. thermophila. Our unique sequences combined contain 2.18 megabases, approximately $10 \%$ of the genomic sequence size of the related protozoan Plasmodium falciparum, and $2.1 \%$ of the $T$. thermophila genomic sequence. As Ich is a ciliate and most closely related to Tetrahymena, this EST resource should represent a good sample of the transcribed fraction of the Ich genome for the estimation of its genome contents as compared with Tetrahymena. Based on the EST sequences, the average $\mathrm{G}+\mathrm{C}$ content of Ich transcribed sequences was found to be $33.4 \%$, even more A/T-rich than those of the closely related hymenostome $T$. thermophila, which has an average $\mathrm{G}+\mathrm{C}$ content of $38 \%$ at protein coding regions [37]. The entire genome of $T$. thermophila was much more $\mathrm{A} / \mathrm{T}$-rich than the transcribed fraction, with a $\mathrm{G}+\mathrm{C}$ content of only $22 \%$ [38]. It is highly probable that the Ich genome is also highly $\mathrm{A} / \mathrm{T}$-rich. To further the analysis, we found approximately $1 \%$ of the unique ESTs sequenced contained simple sequence repeats. The majority of the simple sequence repeats were of di-nucleotide repeats (68.8\%) with AC and AG repeats being the majority. Trinucleotide and tetra-nucleotide repeats accounted for $23.7 \%$ and $7.5 \%$ of the identified microsatellites, respectively (Table 3).

The putative identities of the sequenced ESTs were assessed using BLASTX searches against the non-redundant (NR) database in GenBank [39]. All the search results are summarized in supplemental Table 1 . Of the 4,706 unique ESTs, 2,518 (53.5\%) had significant (E-value $<10^{-}$ 5 ) hits. The remaining 2,188 (46.5\%) EST sequences were not similar to any known sequences. Additional searches using the Swiss-Prot database resulted in putative identities for six additional unknown ESTs (Supplemental Table $1)$.

\section{Identification of putative secretory proteins}

Secretory proteins have been shown to be an important component in many biological processes, including pathogenesis of parasites [40-42]. We therefore searched for transcripts with putative signal peptides (suggestive of 
Table 2: The most abundant ESTs detected from the EST sequencing

\begin{tabular}{llll}
\hline Cluster & \# of Sequences & Putative identities & $\%$ of Total \\
\hline 276 & 764 & Hypothetical protein TTHERM_02 I4I640 from Tetrahymena thermophila & $7.36 \%$ \\
60 & 119 & Hypothetical protein TTHERM_0264I 280 from Tetrahymena thermophila & 1.15 \\
636 & 86 & Unknown & 0.82 \\
602 & 78 & Unknown & 0.75 \\
171 & 48 & Heat shock protein 90 & 0.46 \\
83 & 39 & Zinc finger ZZ type family protein & 0.38 \\
105 & 38 & Unknown & 0.37 \\
279 & 35 & Heat shock protein 90 & 0.34 \\
392 & 34 & Unknown & 0.33 \\
354 & 31 & Heat shock protein 70 (dnaK) & 0.30 \\
203 & 31 & Conserved hypothetical protein from Paracoccus denitrificans & 0.30 \\
219 & 29 & Hypothetical protein PY05925 from Plasmodium yoelii & 0.28 \\
932 & 28 & Unknown & 0.27 \\
75 & 27 & Unknown & 0.26 \\
472 & 24 & ER type HSP70 & 0.23 \\
351 & 23 & Unknown & 0.22 \\
833 & 23 & Unknown protein from Oryza sativa & 0.22 \\
131 & 22 & Unknown & 0.21 \\
6 & 21 & Dynein heavy chain protein & 0.20 \\
45 & 21 & Outer surface protein from Rickettsia typhi & 0.20 \\
\hline
\end{tabular}

peptides of secretory proteins) within the EST set using the program SignalP 3.0 [43]. We found 314 ESTs with signal peptides, representing $6.7 \%$ of the unique sequences. Of these, $180(3.8 \%)$ were from ESTs with no significant (Evalue $<10^{-5}$ ) BLASTX hit to the NR database in GenBank (Supplemental Table 1).

\section{Comparative analysis to related taxa}

The parasite Ich is phylogenetically placed between the protozoan's Plasmodium falciparum and Tetrahymena thermophila. Previous studies using $18 \mathrm{~S}$ rDNA, histone genes, and I-antigens [44-46] suggested that Ich was more related to $T$. thermophila than to $P$. falciparum. Furthermore, $T$. thermophila and Ich share the ciliate nuclear genetic code, while $P$. falciparum uses the standard genetic code for translation. As the entire genome sequence of $P$. falci- parum is available and the macronuclear sequencing project of T. thermophila was just recently completed, we made comparative BLAST analyses against both genome sequences.

The tBLASTx or BLASTX searches of Ich ESTs against the T. thermophila and $P$. falciparum genomes are summarized in Supplemental Table 2, and are presented in Figure 1. As expected based on the phylogenetic relationships, more Ich ESTs were similar to the genome sequences of $T$. Thermophila than to that of $P$. falciparum. Of the 4,706 Ich ESTs, 1,759 sequences were similar (E-value $<10^{-5}$ ) to the T. thermophila genome sequences; whereas 817 were similar to the $P$. falciparum genome sequences. In total, 695 ESTs were similar to both $T$. thermophila and $P$. falciparum genomes, and thus are common to all three protists.

Table 3: A summary of simple sequence repeats identified from the Ich ESTs. Percentages indicated in the parentheses are percentage of each type of repeat among all repeats

\begin{tabular}{cl}
\hline Total number of sequences analyzed & 8,432 \\
\hline Number of dinucleotide repeats & $422(68.8 \%)$ \\
Number of AC repeats & 121 \\
Number of AG repeats & 108 \\
Number of AT repeats & 56 \\
Number of CT repeats & 49 \\
Number of GT repeats & 88 \\
Number of GC repeats & 0 \\
Number of trinucleotide repeats & $145(23.7 \%)$ \\
Number of tetranucleotide repeats & $46(7.5 \%)$ \\
Total number simple sequence repeats & 613 \\
\hline
\end{tabular}




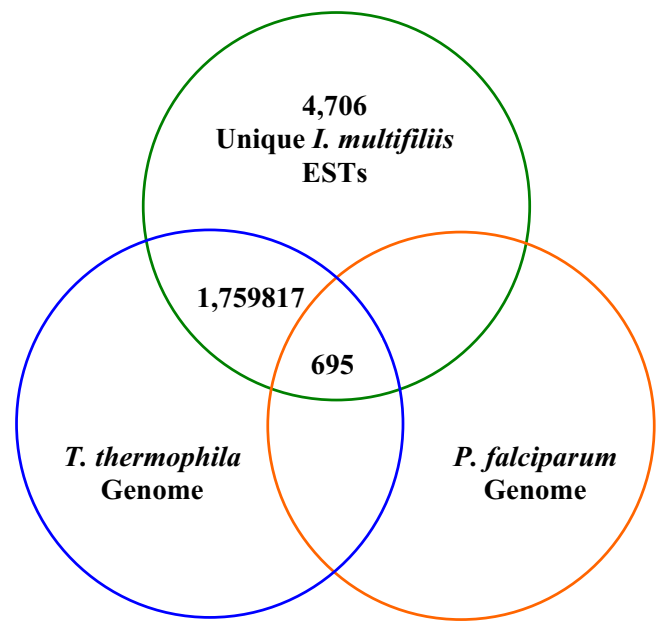

\section{Figure I}

Venn diagram summary of sequence comparisons of the Ich ESTs with Tetrahymena thermophila and Plasmodium falciparum genomes. A total of 4,706 unique Ich ESTs were used as queries yielding I,759 significant (E-value $<10^{-5}$ ) hits to the $T$. thermophila genome, and 817 to the $P$. falciparum genome. $A$ total of 695 sequences were ESTs with common hits to both genomes.

Of the 1,759 significant hits against the T. thermophila genome, 1,673 had been identified with a putative identity using BLASTX searches against the NR database, while the tBLASTx searches against the T. thermophila genome allowed identification of putative identities for additional 86 unique ESTs. Similarly, BLASTX searches against the $P$. falciparum genome allowed identification of 9 additional ESTs. Taken together, the BLAST searches against these two genomes allowed putative identities of 95 additional unique ESTs, bringing the total number of ESTs with significant similarities to known genes to 2,613 .

Such genome searches also revealed that of the 2,518 ESTs that had significant hits in BLASTX searches against the NR database, 845 had no significant hits to the Tetrahymena genome. Clearly, these ESTs were similar to sequences of organisms other than the ciliate Tetrahymena.

These results clearly suggest conservation of a large fraction of gene sequences among the three protozoa parasites, with a higher level of conservation between Ich and the T. thermophila genome than between the Ich genome and the P. falciparum genome; although a significant fraction of gene sequences are also shared between the genomes of $T$. thermophila and $P$. falciparum. The results of this comparative analysis are compatible with existing phylogenetic analyses using several molecular markers such as the $18 \mathrm{~S}$ rDNA, histone genes, and the I-antigens. Obviously, use of a large set of sequences should provide a greater confidence concerning genome evolution. The comparative analysis suggested that the EST resource generated from this study should be useful for phylogenetic analysis and studies concerning genome evolution.

\section{Gene ontology}

The unique Ich sequences were compared to annotations through the Gene Ontology Consortium [47] using the automated software Blast2GO [48]. We were able to obtain GO terms for 1,008 unique sequences using this method. Of these, 304 were contigs and 704 were singletons. Sequence descriptions, gene ontology (GO) and enzyme commission (EC) numbers are summarized in Supplemental Table 3. There were 258 sequences with both GO terms and EC numbers.

Gene ontology graphs using percentages of $2^{\text {nd }}$ level GO terms are presented in Figure 2 under the categories of cellular components (Fig. 2A), molecular functions (Fig. 2B), and biological processes (Fig. 2C). Of the cellular component GO terms, $45 \%$ and $26 \%$ were related directly with cellular and organelle components, respectively. In the category of molecular functions, the vast majority were involved in catalytic activity (41\%) and binding activities (39\%). Under the category of biological processes, $45 \%$ were involved in physiological processes; $43 \%$ were involved in cellular processes, $6 \%$ in regulation of biological processes, $4 \%$ in response to stimuli, and $2 \%$ in development (Figure 2).

\section{Conclusion}

We have produced 8,432 high quality I. multifiliis EST sequences. Sequence analysis indicated the presence of 4,706 unique sequences in the EST set. This should represent a significant fraction of the Ich genes, although the exact gene number of the parasite is unknown at present. The majority of the unique EST sequences had similarities to known genes, making them more amenable to functional analysis. The EST sequences should enhance the effectiveness of molecular studies, especially for gene expression profiling and the analysis of genes involved in virulence and infectivity. Microarrays can now be designed using either cDNA microarray or oligo-based platforms using the EST information. Additionally, the cluster and redundancy information should be useful for further subtraction of the most abundant transcripts included in the cDNA library, making further EST analysis in the parasite more effective.

\section{Methods \\ Samples}

The source of mRNA for this analysis was derived and expanded from a single parasite cloned from the infected 


\section{a.) cellularcomponent}

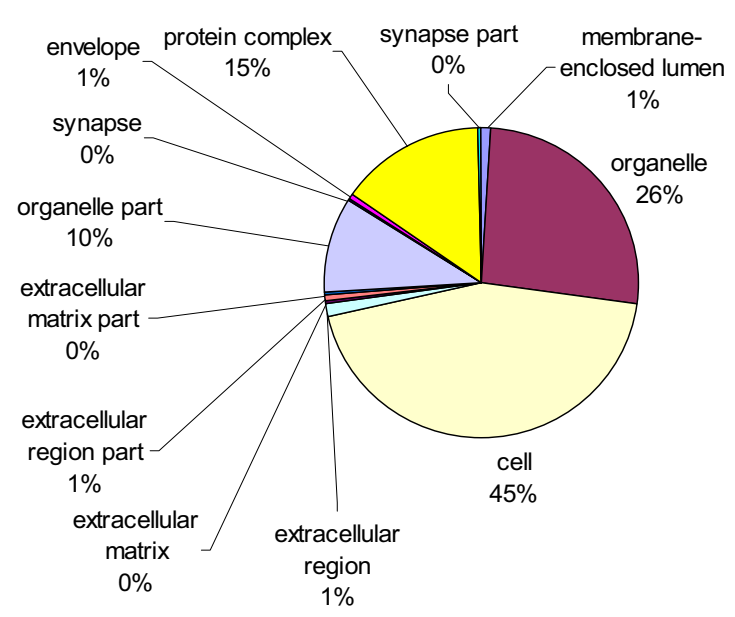

b.) molecular function



c.) biologicalprocess

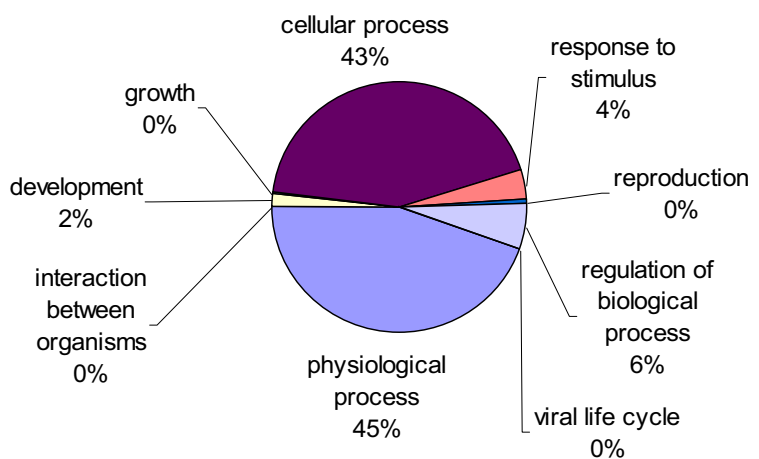

\section{Figure 2}

Pie charts of $2^{\text {nd }}$ level gene ontology (GO) terms. Overall, I,008 unique sequences were annotated using the Blast2GO software and included in the graphs. Each of the three GO categories is presented including cellular component (a), molecular function (b), and biological process (c). 
fish. The source of the original Ichthyophthirius multifiliis was isolated from an infected fish obtained from a local pet shop and the parasite was transmitted to channel catfish held in a 50-1 glass aquarium at the USDA-ARS Aquatic Animal Health Research Laboratory, Auburn, AL. The transmission of I. multifiliis was achieved through Cohabitation of the infected fish with two fingerlings of channel catfish (3 inches in size). When the two catfish were infected, the symptoms of Ich, white spots, started to emerge when trophonts were collected by scraping with a glass slide. Channel catfish infected with maturing trophonts were rinsed in dechlorinated water and the skin was gently scraped to dislodge the parasites. Trophonts were harvested by filtering through a $0.22 \mu \mathrm{m}$ filter to remove fish skin. The trophonts were placed into a Petri dish to allow them to develop into theronts that were used to infect 8 fish each for the collection of trophonts, toments, and theronts, respectively. Trophonts were directly collected from the skin surface of the 8 infected fish. To collect tomonts and theronts, trophonts isolated from fish were placed in Petri dishes and allowed to attach. After replacing the water in the Petri dishes with fresh dechlorinated water to remove contaminating mucus, the trophonts were incubated at $24^{\circ} \mathrm{C}$ for $8 \mathrm{~h}$ to harvest tomonts (32-128 cells/cyst) or $24 \mathrm{~h}$ to harvest theronts. Trophonts, tomonts and theronts were washed with PBS ( $\mathrm{pH} 7.4$ ), concentrated with a centrifuge (Beckman Coulter, Inc., Miami, FL) at $228 \times \mathrm{g}$ for $5 \mathrm{~min}$ and discarded supernatant. After washing 3 times with PBS, parasite samples from the three life stages were stored in liquid nitrogen and used for the isolation of RNA for the construction of normalized cDNA library.

\section{RNA isolation}

Total RNA was isolated from the samples using the TRIzol reagent method from Invitrogen (Carlsbad, CA, USA) according to manufacturer's instructions. Briefly, samples of tomont, theront, and trophont were resuspended after thawing on ice, and $100 \mu \mathrm{l}$ each were combined in a sterile tube to provide a total of $300 \mu \mathrm{l}$ of Ich samples with equal fractions from each of its three life stages. As the major objective of this study was to generate EST resources with maximal efficiency of gene discovery, a pooled sample followed with normalization would allow inclusion of all transcripts in the library while reducing cost for library construction and increasing gene discovery rate. Three milliliters of TRIzol reagent was added to the sample tube. Cells were lysed by repetitively pipetting up and down. RNA was isolated following the manufacturer's protocol. The RNA pellet was resuspended in $100 \mu \mathrm{l}$ of RNase-free double distilled water and divided into $25 \mu \mathrm{l}$ aliquots. RNA aliquots were checked for quality using agarose gel electrophoreses containing formaldehyde.

\section{Normalized library construction}

The Creator Smart cDNA Library Construction Kit from Clontech (Mountain View, CA) and components from the TRIMMER-DIRECT Kit from Evrogen (Moscow, Russia) were used for the construction of the normalized cDNA library. Total RNA concentration was checked on a spectrophotometer and $1 \mu \mathrm{g}$ RNA was combined with $1 \mu \mathrm{l}$ of SMART IV oligonucleotide (Clontech) and $1 \mu$ l CDS-3M adapter (Evrogen) for first-strand cDNA synthesis. The reaction was incubated at $72^{\circ} \mathrm{C}$ for $2 \mathrm{~min}$ followed by immediate cooling on ice for $2 \mathrm{~min}$. Next, $2 \mu \mathrm{l}$ of $5 \times$ first strand buffer, $1 \mu \mathrm{l}$ of DTT ( $20 \mathrm{mM}), 1 \mu \mathrm{l}$ of dNTP mix (10 $\mathrm{mM})$, and $1 \mu \mathrm{l}$ of PowerScript reverse transcriptase were added to the tube and incubated at $42^{\circ} \mathrm{C}$ for $1 \mathrm{~h}$ in a thermal cycler (PTC-100, Bio-Rad, Hercules, CA) then placed on ice. The SMART cDNA cloning system allows the enrichment of full-length cDNA through the use of a 5'linker with 3'-GGG tails. Reverse transcriptase has terminal transferase activity that preferentially adds three additional Cs at the end of first strand CDNA. As a result, the first strand cDNA is able to base pair with the 5'-linker with 3'-GGG tails. Once base paired, the reverse transcriptase would switch the template and extend into the linker sequences allowing PCR amplification of fulllength cDNA using a single primer (the 5'-linker has the same sequences as the linker containing poly $\mathrm{T}$ used for the synthesis of the first strand cDNA). Truncated cDNAs are not able to base pair with the 5'-linker and, therefore, get lost in the PCR amplification of the full-length cDNA.

The first strand cDNA was initially amplified by long-distance PCR (LD-PCR) using hot-start amplification. For the reaction, the following were combined in a reaction tube: $1.5 \mu \mathrm{l}$ of the first strand cDNA, $60 \mu \mathrm{l}$ of sterile deionized water, $7.5 \mu \mathrm{l}$ of $10 \times$ Advantage 2 PCR buffer, $1.5 \mu \mathrm{l}$ of $50 \times$ dNTP mix, $3 \mu$ l of 5 ' PCR primer and $1.5 \mu$ l of $50 \times$ Advantage 2 polymerase mix. The tube was mixed and briefly centrifuged and added to a pre-heated $\left(95^{\circ} \mathrm{C}\right)$ thermal cycler. Cycle settings were $95^{\circ} \mathrm{C}$ for $1 \mathrm{~min}$ followed by 19 cycles of $95^{\circ} \mathrm{C}$ for $7 \mathrm{~s}, 66^{\circ} \mathrm{C}$ for $20 \mathrm{~s}$, and $72^{\circ} \mathrm{C}$ for 5.5 min. The product was analyzed on a $1.1 \%$ agarose gel to determine the sizes and amount of the cDNA products before proceeding to the next step. The LD-PCR reaction was purified and eluted in $30 \mu \mathrm{l}$ of sterile Nanopure water using the QIAquick PCR Purification Kit (Qiagen, Valencia, CA).

For the normalization procedure, the TRIMMER-DIRECT Kit from Evrogen (Moscow, Russia) was used. This system is specially developed to normalize cDNA enriched with full length sequences $[49,50]$. The cDNA from the LD-PCR was quantified $[\sim 100 \mathrm{ng} / \mu \mathrm{l}]$ and $1 \mu \mathrm{l}$ was mixed with $1 \mu \mathrm{l}$ of the $4 \times$ hybridization buffer and $2 \mu$ l of sterile water. The mix was overlaid with mineral oil and incubated for $3 \mathrm{~min}$ at $98^{\circ} \mathrm{C}$ followed by $4 \mathrm{~h}$ at $70^{\circ} \mathrm{C}$. Then, $5 \mu \mathrm{l}$ of $2 \times \mathrm{DSN}$ 
buffer (preheated to $70^{\circ} \mathrm{C}$ ) and 0.25 Kunitz units of DSN enzyme were added and incubated at $70^{\circ} \mathrm{C}$ for $20 \mathrm{~min}$. The DSN enzyme specifically degrades double-stranded molecules. The reaction was inactivated by adding $10 \mu \mathrm{l}$ of DSN stop solution, and sterile water added to a final volume of $40 \mu \mathrm{l}$.

Following normalization, two rounds of PCR were performed using $1 \mu \mathrm{l}$ of the normalization reaction as template. A shorter primer M1 (first 23 bases of the SMART IV oligonucleotide) was used in the first round of PCR with 15 amplification cycles using the same thermal cycling parameters as above; and an even shorter primer M2 (first 20 bases of the SMART IV oligonucleotide) was used in the second round of PCR for 15 amplification cycles of $95^{\circ} \mathrm{C}$ for $7 \mathrm{~s}, 64^{\circ} \mathrm{C}$ for $20 \mathrm{~s}$, and $72^{\circ} \mathrm{C}$ for $5.5 \mathrm{~min}$. Products were checked on a $1.1 \%$ agarose gel. The PCR products were quantified and $3 \mu \mathrm{g}$ were used for treatment with proteinase K. All the subsequent procedures including proteinase K treatment, restriction digestion with $S f i \mathrm{I}$, size fractionation, and ligation followed the manufacture's instructions (Clontech). The cDNA was ligated to the pDNR-LIB vector. Electroporation (MicroPulser, BioRad, Hercules, CA) was performed using DH12S electrocompetent cells following supplier's instructions (Invitrogen). A total of approximately 700,000 primary recombinant clones were obtained, and the library was amplified, titered, and stored in glycerol stocks in a $-80^{\circ} \mathrm{C}$ freezer.

\section{Plasmid isolation and EST sequencing}

Independent colonies were picked and grown for $20 \mathrm{~h}$ at $37^{\circ} \mathrm{C}$ in $1.2 \mathrm{ml} \mathrm{LB}$ broth containing $30 \mu \mathrm{g} / \mathrm{ml}$ chloramphenicol. Plasmid DNA was isolated using the Perfectprep Plasmid 96 Vacuum Direct Bind Kit from Eppendorf (Westbury, NY). Plasmids were stored at $-20^{\circ} \mathrm{C}$ until usage. The cDNA inserts were directionally sequenced from the 5'-end of the cDNAs using universal M13(-21) primer and the BigDye terminator sequencing kit version 3.1 from Applied Biosystems (Foster City, CA) on a 3130XL DNA analyzer (Applied Biosystems).

\section{Sequence analysis}

Base calling was performed using the Phred program [30,31] at quality cut-off set at Phred 20. Raw sequences were then imported into the Vector NTI Advance 10 software (Invitrogen) and were subjected to trimming of vector sequences and 5'adapter sequences using default settings. Afterwards, poly (A) tails were trimmed where necessary and sequences less than 100 bases were removed. Contigs were built in Vector NTI ContigExpress using default settings. All unique sequences were compared to the GenBank database using BLASTX in the nonredundant (NR), Swiss-Prot, and Plasmodium falciparum 3D7 genome database. For comparison to the Tetrahy- mena thermophila SB210 genome, tBLASTx was used. The cut-off for sequence similarity used was E-value $<10^{-5}$ for all analyses. Ciliate nuclear translation code was used in the BLAST searches. Search results from genome comparisons were summarized using a Venn diagram.

Gene ontology (GO) annotations were assigned using the program Blast2GO [48]. BLASTX results were loaded into the program and the default settings were used to assign $\mathrm{GO}$ terms to all unique sequences. From these annotations, pie charts were made using $2^{\text {nd }}$ level GO terms based on biological process, molecular function, and cellular component.

Putative secretory proteins and signal peptides were identified using both neural networks and hidden Markov model methods in SignalP 3.0 [43]. All 4,706 unique ESTs were used as the tester sequences. Open reading frames were predicted using both OrfPredictor [51] and BLASTX, with ciliate nuclear genetic code for ESTs of known genes and just OrfPredictor with unknown ESTs. The resulting deduced protein sequences from the ORFs were uploaded into SignalP 3.0. Sequences were identified as putatively secretory, predicted with signal peptides if both $D$-score in the neural network model and prediction probability in the hidden Markov model were significant.

Total lengths of all ESTs, G+C\% content and simple repetitive elements were estimated using the Repeatmasker program [52].

\section{Accession numbers}

All Ich EST sequences were submitted to the dbEST database of NCBI. Continuous accession numbers are from EG957858-EG966289.

\section{Authors' contributions}

JWA, CA and ZJL planned the experiment and drafted the manuscript. HK, PL and PX provided technical assistance including cDNA library construction and sequencing support. PK and DX provided technical support and valuable Ich knowledge along with sample preparations. All were involved in final manuscript editing.

\section{Additional material}

\section{Additional file 1}

Supplemental Table 1, Excel spreadsheet; Table of I. multifiliis unique EST sequences; Provided information includes I. multifiliis BLASTX top hits to the non-redundant database in GenBank with unique EST name and accession numbers. Also included are significant protein domain comparisons to the Swiss-Prot database. Putative secretory proteins are highlighted.

Click here for file

[http://www.biomedcentral.com/content/supplementary/1471-

2164-8-176-S1.xls] 


\section{Additional file 2}

Supplemental Table 2, Excel spreadsheet; Summary of BLAST searches of the Ich ESTs against Tetrahymena thermophila and Plasmodium falciparum genomes. Provided information includes I. multifiliis BLASTX top hits to the non-redundant database in GenBank with unique EST name, tBLASTx top hits to the $\mathrm{T}$. thermophila genome, and BLASTX top hits to the $\mathrm{P}$. falciparum genome sequences. This table correlates with the Venn diagram in figure 1.

Click here for file

[http://www.biomedcentral.com/content/supplementary/14712164-8-176-S2.xls]

\section{Additional file 3}

Supplemental Table 3, Excel spreadsheet; Table of gene ontology (GO) profiles; Provided information includes unique EST name, accession numbers, BLASTX top hit, GO identification numbers and enzyme commission (EC) numbers.

Click here for file

[http://www.biomedcentral.com/content/supplementary/14712164-8-176-S3.xls]

\section{Acknowledgements}

This project was supported by a Specific Cooperative Agreement with USDA ARS Aquatic Animal Health Laboratory under the Contract Number 58-6420-5-030, and in part by CSREES from a grant of USDA NRI Animal Genome Tools and Resources Program (award \# 2006-35616-16685) to support the first year stipend of JWA. We are grateful for an equipment grant from the National Research Initiative Competitive Grant no. 200535206-15274 from the USDA Cooperative State Research, Education, and Extension Service.

\section{References}

I. MacLennan RF: Observations on the life cycle of Ichthyophthirius, a ciliate parasitic on fish. Northwestern Scientist 1935, 9:12-14.

2. Hines RS, Spira DT: Ichthyophthiriasis in the mirror carp Cyprinus carpio (L.) V. Acquired immunity. J Fish Biology 1974, 6:373-378.

3. Nigrelli RF, Pokorny KS, Ruggieri GD: Notes on Ichthyophthirius multifilis, a ciliate parasitic on fresh-water fishes, with some remarks on possible physiological races and species. Trans Ame Microscopical Soc 1976, 95(4):607-613.

4. Matthews RA: Ichthyophthirius multifiliis Fouquet and Ichthyophthiriosis in Freshwater Teleosts. Adv parasitol 2005, 59:159-241.

5. Xu DH, Klesius PH: Protective effect of cutaneous antibodyproduced by channel catfish, Ictalurus punctatus (Rafinesque), immune to Ichthyophthirius multifiliis Fouquet on cohabited non-immune catfish. J fish dis 2003, 26(5):287-29I

6. Xu DH, Klesius PH, Panangala VS: Induced cross-protectionin channel catfish, Ictalurus punctatus (Rafinesque), against different immobilization serotypes of Ichthyophthirius multifiliis. J fish dis 2006, 29(3): | |3|-|38.

7. $\mathrm{Xu} \mathrm{DH,} \mathrm{Klesius} \mathrm{PH,} \mathrm{Shelby} \mathrm{RA:} \mathrm{Immune} \mathrm{responses} \mathrm{and} \mathrm{hostpro-}$ tection of channel catfish, Ictalurus punctatus (Rafinesque), against Ichthyophthirius multifiliis after immunization with live theronts and sonicated trophonts. J fish dis 2004, 27(3):|35-|4|.

8. $\mathrm{Xu} \mathrm{DH}$, Klesius PH, Shoemaker CA: Effect of lectins on theinvasion of Ichthyophthirius theront to channel catfish tissue. Dis Aquat organisms 200I, 45(2): II I-I20.

9. Xu DH, Klesius PH, Shoemaker CA: Cutaneous antibodies fromchannel catfish, Ictalurus punctatus (Rafinesque), immune to Ichthyophthirius multifiliis (Ich) may induce apoptosis of Ich theronts. J fish dis 2005, 28(4):2। 3-220.
10. Dickerson HW, Clark TG, Findly RC: Ichthyophthirius multifiliis has membrane-associated immobilization antigens. J Protozool 1989, 36(2): 159-164.

II. Dickerson HW, Clark TG, Leff AA: Serotypic variationamong isolates of Ichthyophthirius multifiliis based on immobilization. J Eeukaryotic Microbiol 1993, 40(6):816-820.

12. Ekless L, Matthews R: Ichthyophthirius multifiliis: axenic isolation and short-term maintenance in selected monophasic media. J fish dis 1993, 16:437-447.

13. Burkart M, Clark T, Dickerson H: Immunization of channelcatfish, Ictalurus punctatus Rafinesque, against Ichthyophthirius multifiliis (Fouquet): killed versus live vaccines. J Fish Biol 1990 , I3:40|-4I0.

14. Houghton G, Matthews RA: Immunosuppression of carp (Cyprinus carpio L.) to ichthyophthiriasis using the corticosteroid triamcinolone acetonide. Vet Immunol Immunopathol I986, I 2(I4):4I3-4I9.

15. Xu DH, Klesius PH: Two year study on the infectivity of Ichthyophthirius multifiliis in channel catfish Ictalurus punctatus. Dis Aquat Organisms 2004, 59(2): I3I-I34.

16. Deng Y, Dong Y, Thodima V, Clem RJ, Passarelli AL: Analysis and functional annotation of expressed sequence tags from the fall armyworm Spodoptera frugiperda. BMC genomics 2006, $7(1): 264$.

17. Govoroun M, Le Gac F, Guiguen Y: Generation of a large scale repertoire of Expressed Sequence Tags (ESTs) from normalised rainbow trout cDNA libraries. BMC genomics 2006, 7:196.

18. Hagen-Larsen H, Laerdahl JK, Panitz F, Adzhubei A, Hoyheim B: An EST-based approach for identifying genes expressed in the intestine and gills of pre-smolt Atlantic salmon (Salmo salar). BMC genomics 2005, 6: 171 .

19. Kim TH, Kim NS, Lim D, Lee KT, Oh JH, Park HS, Jang GW, Kim HY, Jeon $\mathrm{M}$, Choi $\mathrm{BH}$, et al:: Generation and analysis of large-scale expressed sequence tags (ESTs) from a full-length enriched cDNA library of porcine backfat tissue. BMC genomics 2006 , 7:36.

20. Vizcaino JA, Gonzalez FJ, Suarez MB, Redondo J, Heinrich J, DelgadoJarana J, Hermosa R, Gutierrez S, Monte E, Llobell A, et al.: Generation, annotation and analysis of ESTs from Trichoderma harzianum CECT 24I3. BMC genomics 2006, 7:193.

21. Gonzalez SF, Chatziandreou N, Nielsen ME, Li W, Rogers J, Taylor R, Santos $Y$, Cossins A: Cutaneous immune responses in the common carp detected using transcript analysis. Mol Immunol 2007, 44(7): 1675-1690.

22. La Claire JW 2nd: Analysis of expressed sequence tagsfrom the harmful alga, Prymnesium parvum (Prymnesiophyceae, haptophyta). Mar Biotechnol (NY) 2006, 8(5):534-546.

23. Perez F, Ortiz J, Zhinaula M, Gonzabay C, Calderon J, Volckaert FA Development of EST-SSR markers by data mining in three species of shrimp: Litopenaeus vannamei, Litopenaeus stylirostris, and Trachypenaeus birdy. Mar Biotechnol (NY) 2005, 7(5):554-569.

24. Brenner ED, Katari MS, Stevenson DW, Rudd SA, Douglas AW, Moss WN, Twigg RW, Runko SJ, Stellari GM, McCombie WR, et al.: EST analysis in Ginkgo biloba: an assessment of conserved developmental regulators and gymnosperm specific genes. $B M C$ genomics 2005, 6: 143

25. Gandhe AS, Arunkumar KP, John SH, Nagaraju J: Analysis ofbacteria-challenged wild silkmoth, Antheraea mylitta (lepidoptera) transcriptome reveals potential immune genes. $B M C$ genomics 2006, 7: 184 .

26. Hecht J, Kuhl H, Haas SA, Bauer S, Poustka AJ, Lienau J, Schell $H$, Stiege AC, Seitz V, Reinhardt R, et al: Gene identification and analysis of transcripts differentially regulated in fracture healing by EST sequencing in the domestic sheep. $B M C$ genomics 2006, 7:172.

27. Nelson RT, Shoemaker R: Identification and analysis of gene families from the duplicated genome of soybean using EST sequences. BMC genomics 2006, 7:204.

28. Ribichich KF, Georg RC, Gomes SL: Comparative EST analysis provides insights into the basal aquatic fungus Blastocladiella emersonii. BMC genomics 2006, 7:177.

29. Boguski MS, Lowe TM, Tolstoshev CM: dbEST - database for "expressed sequence tags". Nat Genet 1993, 4(4):332-333. 
30. Ewing B, Green P: Base-calling of automated sequencer traces using phred. II. Error probabilities. Genome Res 1998, 8(3): $186-194$.

31. Ewing B, Hillier L, Wend MC, Green P: Base-calling of automated sequencer traces using phred. I. Accuracy assessment. Genome Res 1998, 8(3): I75-185.

32. Kocabas AM, Li P, Cao D, Karsi A, He C, Patterson A, Ju Z, Dunham RA, Liu Z: Expression profile of the channel catfish spleen analysis of genes involved in immune functions. Mar Biotechnol (NY) 2002, 4(6):526-536.

33. Karsi A, Cao D, Li P, Patterson A, Kocabas A, Feng J, Ju Z, Mickett KD, Liu Z: Transcriptome analysis of channel catfish (Ictalurus punctatus): initial analysis of gene expression and microsatellite-containing cDNAs in the skin. Gene 2002, 285(I2): $157-168$

34. Cao D, Kocabas A, Ju Z, Karsi A, Li P, Patterson A, Liu Z: Transcriptome of channel catfish (Ictalurus punctatus): initial analysis of genes and expression profiles of the head kidney. Anim Genet 2001, 32(4): 169-188.

35. Ju Z, Karsi A, Kocabas A, Patterson A, Li P, Cao D, Dunham R, Liu Z Transcriptome analysis of channel catfish (Ictalurus punctatus): genes and expression profile from the brain. Gene 2000 26 I (2):373-382

36. Quilang J, Wang S, Li P, Abernathy J, Peatman E, Wang Y, Wang L, Shi $Y$, Wallace R, Guo X, Liu Z: Generation and analysis ofESTs from the eastern oyster, Crassostrea virginica Gmelin and identification of microsatellite and SNP markers. BMC Genomics 2007 in press.

37. Wuitschick JD, Karrer KM: Analysis of genomic G + C content codon usage, initiator codon context and translation termination sites in Tetrahymena thermophila. I Eukaryotic Microbiol 1999, 46(3):239-247.

38. Eisen JA, Coyne RS, Wu M, Wu D, Thiagarajan M, Wortman JR, Badger JH, Ren $\mathrm{Q}$, Amedeo P, Jones KM, et al:: MacronuclearGenome Sequence of the Ciliate Tetrahymena thermophila, a Model Eukaryote. PLoS Biol 2006, 4(9):e286.

39. The National Center for Biotechnology Information [http:// www.ncbi.nlm.nih.gov/]

40. O'Donnell RA, Blackman MJ: The role of malaria merozoite proteases in red blood cell invasion. Curr Opinion Microbiol 2005 8(4):422-427.

41. Prato M, Giribaldi G, Polimeni M, Gallo V, Arese P: Phagocytosis of hemozoin enhances matrix metalloproteinase- 9 activity and TNF-alpha production in human monocytes: role of matrix metalloproteinases in the pathogenesis of falciparum malaria. J Immunol 2005, I 75( I 0):6436-6442.

42. Tosini F, Trasarti E, Pozio E: Apicomplexa genes involvedin the host cell invasion: the Cpal 35 protein family. Parassitologia 2006, 48(I-2): 105-107.

43. Bendtsen JD, Nielsen H, von Heijne G, Brunak S: Improved prediction of signal peptides: SignalP 3.0. J Mol Biol 2004 340(4):783-795.

44. Wright AD, Lynn DH: Phylogeny of the fish parasite Ichthyophthirius and its relatives Ophryoglena and Tetrahymena (Ciliophora, Hymenostomatia) inferred from I8S ribosomal RNA sequences. Mol Biol Evol I995, I 2(2):285-290.

45. Van Den Bussche RA, Hoofer SR, Drew CP, Ewing MS: Characterization of histone $\mathrm{H} 3 / \mathrm{H} 4$ gene region and phylogenetic affinity of Ichthyophthirius multifiliis based on H4 DNA sequence variation. Mol Phylogenet Evol 2000, I4(3):46 I-468.

46. Clark TG, McGraw RA, Dickerson HW: Developmental expression of surface antigen genes in the parasitic ciliate Ichthyophthirius multifiliis. Proc Natl Acad Sci USA 1992, 89(14):6363-6367.

47. Ashburner M, Ball CA, Blake JA, Botstein D, Butler H, Cherry JM, Davis AP, Dolinski K, Dwight SS, Eppig JT, et al.: Gene ontology: tool for the unification of biology. The Gene Ontology Consortium. Nat Genet 2000, 25(I):25-29.

48. Conesa A, Gotz S, Garcia-Gomez JM, Terol J, Talon M, Robles M: Blast2GO: a universal tool for annotation, visualization and analysis in functional genomics research. Bioinformatics (Oxford, England) 2005, 2 I ( I 8):3674-3676.

49. Zhulidov PA, Bogdanova EA, Shcheglov AS, Vagner LL, Khaspekov GL, Kozhemyako VB, Matz MV, Meleshkevitch E, Moroz LL, Lukyanov SA, et al:: Simple cDNA normalization using kamchatka crab duplex-specific nuclease. Nucl Acids Res 2004, 32(3):e37.
50. Liu Z: Transcriptome characterization through the generation and analysis of expressed sequence tags: Factors to consider for a successful EST project. Israel J Aquaculture - Bamidgeh 2006, 58(4):328-340.

5I. Min XJ, Butler G, Storms R, Tsang A: OrfPredictor:predicting protein-coding regions in EST-derived sequences. Nucl Acids Res 2005:W677-680.

52. Smit A, Hubley R, Green P: RepeatMasker Open - 3.0. 1996 [http://www.repeatmasker.org].
Publish with Biomed Central and every scientist can read your work free of charge

"BioMed Central will be the most significant development for disseminating the results of biomedical research in our lifetime. "

Sir Paul Nurse, Cancer Research UK

Your research papers will be:

- available free of charge to the entire biomedical community

- peer reviewed and published immediately upon acceptance

- cited in PubMed and archived on PubMed Central

- yours - you keep the copyright

Submit your manuscript here:

http://www.biomedcentral.com/info/publishing_adv.asp
BioMedcentral 